\title{
Management of malignant pleural effusion: challenges and solutions
}

This article was published in the following Dove Press journal:

Cancer Management and Research

23 June 2017

Number of times this article has been viewed

\author{
Erika Penz' \\ Kristina N Watt' \\ Christopher A Hergott ${ }^{2}$ \\ Najib M Rahman ${ }^{3}$ \\ loannis Psallidas ${ }^{3}$ \\ 'Division of Respirology, \\ Department of Medicine, University \\ of Saskatchewan, Saskatoon, SK, \\ 2Division of Respirology, Department \\ of Medicine, University of Calgary, \\ Calgary, AB, Canada; ${ }^{3}$ Oxford \\ Centre for Respiratory Medicine, \\ Respiratory Trials Unit, Oxford \\ University, Oxford, UK
}

\begin{abstract}
Malignant pleural effusion (MPE) is a sign of advanced cancer and is associated with significant symptom burden and mortality. To date, management has been palliative in nature with a focus on draining the pleural space, with therapies aimed at preventing recurrence or providing intermittent drainage through indwelling catheters. Given that patients with MPEs are heterogeneous with respect to their cancer type and response to systemic therapy, functional status, and pleural milieu, response to MPE therapy is also heterogeneous and difficult to predict. Furthermore, the impact of therapies on important patient outcomes has only recently been evaluated consistently in clinical trials and cohort studies. In this review, we examine patient outcomes that have been studied to date, address the question of which are most important for managing patients, and review the literature related to the expected value for money (cost-effectiveness) of indwelling pleural catheters relative to traditionally recommended approaches.
\end{abstract}

Keywords: malignant pleural effusion, therapeutics, cost-effectiveness, quality of life

\section{Introduction}

Malignant pleural effusion (MPE) affects many patients around the world and has significant morbidity and mortality associated with it. ${ }^{1}$ It is estimated to affect 150,000 people each year in the US and over 100,000 people in Europe. ${ }^{2,3}$ A recent retrospective analysis using the Healthcare Cost and Utilization Project National Inpatient Sample database identified 126,825 hospital admissions for MPE in 2012. ${ }^{1}$ Although there are no studies to date documenting the rate of hospitalizations for all patients with MPE, clinical experience suggests that a vast majority of patients with MPE seek medical care and are often managed for their symptoms in hospital. Despite its longstanding recognition, management has remained predominantly palliative in nature. Advances in therapeutics have been slow, with more growth in the last 15 years. Indwelling pleural catheters (IPCs) have developed an increasingly predominant role in the management of MPE, with proven effectiveness in symptom management ${ }^{4,5}$ allowing recent guidelines to endorse their use. ${ }^{6,7}$ In this review, we examine which patient outcomes have been studied, address the question of which are most important for managing patients, and review the literature related to the expected value for money (cost-effectiveness) of IPCs relative to traditionally recommended approaches.

Room 537, Ellis Hall, Royal University Hospital, 103 Hospital Drive, Saskatoon, SK S7N 0W8, Canada

Tel + I 3068441009 ext 4

Fax +I 3068441532

Email erika.penz@usask.ca

\section{Epidemiology and etiology}

MPE is defined as pleural fluid containing malignant cells. Paramalignant effusion is defined as an effusion that is not a direct result of neoplastic involvement of the submit your manuscript Dovepress if in 5 
pleura, but rather indirectly related, including but not limited to postobstructive pneumonia, lymphatic obstruction secondary to mediastinal lymphadenopathy, or effusion secondary to pulmonary embolism. MPE is a complication of a number of cancers, most commonly lung, followed by breast, lymphoma, gynecological malignancies, and mesothelioma. ${ }^{8}$ Adenocarcinomas of the lung and breast account for approximately $50 \%-65 \%$ of MPEs. ${ }^{1,2,8,9}$ Malignant effusions develop in about $30 \%$ of patients with lung cancer ${ }^{6}$ and $7 \%-11 \%$ of those with breast cancer. ${ }^{10-12}$ Approximately 7\%-11\% also occur in the setting of an unknown primary malignancy. ${ }^{13-17}$ MPE is a sign of advanced-stage disease often resulting in poor patient prognosis, with median survival ranging from just over 1 month to 12 months based on underlying malignancy and risk stratification. ${ }^{18,19}$ Patients with small-cell lung carcinoma and MPE have a worse prognosis than those with limited-stage disease without malignant effusions. ${ }^{20}$ Lymphoma patients found to have MPE on initial diagnosis have a higher risk of disease recurrence postchemotherapy. ${ }^{21}$ The shortest survival rates are observed in lung cancer and the longest in those with mesothelioma and hematological malignancies. ${ }^{19}$ Other factors associated with survival include the extent of tumor involvement within the pleura, the characteristics and biomarkers of the pleural fluid, the response of the malignancy to systemic therapy, and the baseline functional status of the patient. ${ }^{19}$

\section{Pathogenesis and clinical presentation}

Pleural involvement in malignancy develops from several mechanisms that are not fully understood. MPE can arise from direct tumor invasion from adjacent structures, as often seen in breast carcinoma, non-Hodgkin's lymphoma, and mesothelioma. Tumor emboli or hematogenous tumor cells spreading to the visceral pleura can result in subsequent seeding to the parietal pleura. Their presence can impair lymphatic drainage, leading to pulmonary atelectasis and accumulation of fluid in the pleural space. ${ }^{8,22-25}$ The release of cytokines and upregulation of angiogenic growth factors (eg, vascular endothelial growth factor [VEGF], CCL2, and osteopontin) stimulated by malignant cells can alter compartmental oncotic pressures and pleural and vascular permeability. ${ }^{26-28}$ This contributes to further fluid accumulation and can develop into hemorrhagic malignant effusions. ${ }^{8}$

Patients with MPE most often present with progressive dyspnea, but less than a quarter are asymptomatic from a respiratory perspective. ${ }^{13,29}$ In addition to constitutional symptoms commonly associated with malignancy, patients have been known to suffer from chest pain and discomfort, followed by cough and hemoptysis in descending frequency. ${ }^{13,30,31}$ Many of these symptoms arise from a reduction in chest wall and diaphragm compliance, as well as lung volume.

\section{Management}

Ideal therapy for MPE patients should improve dyspnea and quality of life, be minimally invasive (or at best noninvasive), well tolerated, affordable, and eliminate the need for time in hospital. A number of therapeutic options are available to alleviate patient symptoms and improve quality of life, including needle drainage with repeat thoracentesis, chest-tube thoracostomy, or thoracoscopy with pleurodesis (chemical or mechanical), and/or IPCs.

\section{Thoracentesis}

Thoracentesis is a percutaneous procedure in which a small (approximately $250 \mathrm{~mL}$ is sufficient for diagnostic purposes) or large volume (often up to 1,500 $\mathrm{mL}$, based on the authors' clinical practice for therapeutic purposes) of pleural fluid is drained through the chest wall using a needle or small-bore soft-tipped catheter.

\section{Effectiveness/advantages}

Obvious advantages to this approach are that the procedure can be performed easily in an outpatient setting without extensive resources (no anesthesia support or special monitoring and only simple thoracentesis tray and drainage bottles), and the patient can return home shortly thereafter. Thoracentesis is effective in draining a reasonably large amount of pleural fluid (often recommended to no more than $1.5 \mathrm{~L}$ at a time), and with the use of ultrasound can be directed to areas of fluid accumulation, particularly if there is more than one pocket of fluid. The procedure is straightforward to teach and can generally be performed safely with minimal training. For the majority of patients, drainage of the effusion with thoracentesis reduces dyspnea and/or pain almost immediately.

\section{Complications/disadvantages}

The main disadvantage to simple thoracentesis is that it is not effective in preventing recurrence of pleural fluid accumulation, and thus is seen as a temporizing solution. For patients living in remote areas with limited access to health care services, this temporizing solution in a condition with significant probability of recurrence is less than ideal. The complication of pneumothorax is low (less than $2 \%$ ) with the use of ultrasound. ${ }^{1,2}$ Bleeding and infection are uncommon 
and are largely dependent on operator experience, technique, and patient variables. . $^{4,8}$

\section{Chest-tube thoracostomy with pleurodesis}

Chest-tube thoracostomy is performed with the intent to evacuate pleural fluid from the pleural space and enable apposition of the visceral and parietal pleura. Rarely is complete evacuation of the pleural cavity sufficient to control the effusion in the long term, and compared with instillation of a sclerosing agent, drainage alone is less effective in preventing reaccumulation. ${ }^{9}$ Consequently, the primary role of chest-tube thoracostomy is to empty the pleural space prior to instillation of a sclerosing agent, with the goal of obliterating the visceral/parietal space and preventing reaccumulation of fluid.

\section{Effectiveness/advantages}

The effectiveness of thoracostomy with pleurodesis using a number of different sclerosing agents has been studied in clinical trials, ${ }^{4,32,33}$ and all have found thoracostomy with pleurodesis to be effective in reducing dyspnea and improving quality of life. In these trials, with follow-up of 3-12 months, pleurodesis was unsuccessful in up to $10 \%-30 \%$ of patients, mainly due to ongoing or incomplete pleural drainage ( $>300 \mathrm{~mL}$ per day), presence of trapped lung, chest-tube displacement, or death. Once pleurodesis had been obtained, the rate of sustained pleurodesis (no need for further pleural interventions) was $68 \%-78 \% ., 33$ Median time to pleurodesis was 29 days, ranging 8-223 days.

\section{Complications/disadvantages}

Risks of thoracostomy with pleurodesis include pain and fever in approximately $26 \%$ and $30 \%$, respectively, according to a Cochrane review. ${ }^{34}$ Respiratory failure has been reported in $4 \%$ of patients receiving talc slurry, ${ }^{35}$ with much lower risk if large-particle talc is used. ${ }^{36}$ Thoracostomy drainage followed by talc pleurodesis has also historically required hospitalization, with median length of stay of 4 days reported in both TIME2 and AMPLE trials. ${ }^{4,32}$

\section{Pleurodesis}

Multiple sclerosing agents have been studied, including doxycycline, tetracycline, bleomycin, and talc, with the preferred and most common agent used now being talc. ${ }^{6,10}$ A Cochrane review and network meta-analysis published in 2016 reviewed 41 studies evaluating 16 pleurodesis methods and included 2,345 participants. ${ }^{34}$ In the majority of cases, there was no evidence to support any difference among agents in terms of pleurodesis. However, in 10 direct comparisons of individual methods, a number of agents were less effective than talc poudrage at inducing pleurodesis, including bleomycin (odds ratio [OR] 9.7, 95\% confidence interval [CI] 2.1-44.78), tetracycline (OR 12.1, 95\% CI 1.32-111.3), mustine (OR 8, 95\% CI 1.4-45.76), and doxycycline (OR $42.69,95 \%$ CI 2.13-856.6). In the network comparison of all 16 agents, the estimated rank of talc poudrage was second, with a $95 \%$ credible interval of $1-5$. In the comparison between talc slurry and talc poudrage among three studies, there was weak evidence to suggest that talc slurry may be less effective at pleurodesis (OR 1.31, 95\% CI 0.92-1.85).

\section{Medical thoracoscopy/Video-assisted thoracoscopic surgery (VATS) with pleurodesis}

Medical thoracoscopy or pleuroscopy is a procedure performed under conscious sedation and local anesthesia whereby one or more trocars are inserted into the pleural space in the midaxillary line (between the fourth and seventh ribs), with the patient lying in the lateral decubitus position. VATS is similar to medical thoracoscopy, except that it is performed using larger trocars, under general anesthesia in the operating room, and involves single-lung ventilation through a dual-lumen tube. ${ }^{37}$

\section{Effectiveness/advantages}

Advantages of this approach over traditional chest-tube drainage is that visualization and drainage of the pleural space can occur, pleural biopsies can be obtained, and delivery of a sclerosing agent can occur before a chest tube is inserted through the trocar.

\section{Complications/disadvantages}

Complications associated with this procedure include pneumothorax, subcutaneous emphysema, pain, fever, and rarely empyema, sepsis, and death. ${ }^{38}$

\section{VATS with pleurodesis Effectiveness/advantages}

Similar to thoracoscopy, an advantage with VATS is that a more complete view of the pleural surface can be achieved, pleural and/or lung biopsy can be performed, as well as biopsy of selected hilar lymph nodes, and treatment can be administered all within one procedure. For complicated pleural spaces, including trapped lung due to adhesions, lysis of adhesions and surgical pleurodesis can be performed, 
and in some select cases more advanced techniques, such as pleurectomy/decortication, may be performed.

It is generally considered a safe procedure with low morbidity. ${ }^{39,40}$ In a comparison of patients treated with VATS pleurodesis compared to tube thoracostomy, duration of chest-tube drainage was shorter in patients receiving VATS pleurodesis. ${ }^{41}$ In a retrospective study reporting treatment outcomes for patients undergoing VATS talc pleurodesis for MPE, successful pleurodesis was reported in 93\% (558 of 602 individuals) with median follow-up of 64 months. ${ }^{42}$

\section{Complications/disadvantages}

Although generally considered safe with low morbidity, the procedure cannot be tolerated by every patient and would not be an option for patients who could not tolerate single-lung ventilation or who have such poor performance status (PS). Postoperative complications have been reported in 3\%-25\%, and included chest pain (25\%), fever (15\%), prolonged air leak (4\%), ${ }^{40}$ and empyema $(1.5 \%-4.5 \%) .{ }^{40,43}$ Hospitalization is required for VATS and has been reported as a mean of 7-10 days in different studies (range 2-21 days). ${ }^{39,43}$ In a randomized trial evaluating VATS partial pleurectomy versus talc pleurodesis in mesothelioma patients, no difference in survival was seen and much higher rates of perioperative complications reported in the VATS partial pleurectomy group. ${ }^{37}$ In general, surgery is not considered first-line treatment in patients with MPE. ${ }^{44}$

\section{IPCs}

IPCs have been the newest alternative intervention to managing patient symptoms with MPE. The IPC is a type of silicone tube placed in the pleural cavity, tunneled subcutaneously with a capped one-way valve at the distal end. It allows outpatient drainage and addresses patient symptoms by removing the fluid. Leading guidelines have advocated the use of IPCs for the symptomatic management of MPE, specifically for those with trapped lung or previously failed pleurodesis. ${ }^{7,44}$ Drainage is guided by symptoms, offering a sense of control to most patients. The optimal schedule of MPE drainage through an IPC is still not clear, although recent studies, including the ASAP trial, have been published and suggest daily drainage superior to every other day in terms of autopleurodesis rate and time to pleurodesis. ${ }^{45}$ Given the ease with which IPCs are inserted and managed, coupled with the benefits of placement in an outpatient setting and minimal contraindications (ie, active pleural infection), they have become a preferred and dominant management option in many centers worldwide with the technical expertise to insert them.

\section{Effectiveness/advantages}

There have been numerous studies that have reported experience with IPCs in MPE, with only a few randomized clinical trials reported to date. ${ }^{4,5,33}$ Putnam et al showed that IPCs provided equivalent improvement in both dyspnea and quality of life to doxycycline pleurodesis in 144 patients. ${ }^{33}$ The recently published TIME2 trial evaluating their use showed comparable control of breathlessness and quality of life when compared to inpatient talc pleurodesis, but shorter length of hospital stay. ${ }^{4}$ In most patients, IPCs have resulted in avoidance of further pleural interventions and associated costs. ${ }^{4,33,46}$

IPCs have been shown significantly to improve validated dyspnea and quality of life scores (Medical Research Council, European Organisation for Research and Treatment of Cancer Lung Cancer 13 and Core Quality of Life 30 questionnaires) at 2 weeks with persistent and improved scores at 14 weeks. ${ }^{47}$ In addition, patients who completed the functional assessment of chronic illness therapy: treatment satisfaction - general (FACITTS-G) survey demonstrated that they were satisfied with IPC treatment for their MPE. ${ }^{48}$ In patients with trapped lung, IPC drainage improved symptoms in $48 \%-90 \%$ of cases. ${ }^{4,49,50}$ Autopleurodesis following IPC use was seen in almost half (45.6\%) of the 943 cases analyzed in the meta-analysis by Van Meter et al, and average time to pleurodesis was 52 days. ${ }^{48}$ Even in the presence of trapped lung, autopleurodesis was seen, although less frequently. ${ }^{50-52}$ There is also evidence that IPCs can be used for patients on chemotherapy without increasing the risk of complications. $^{53}$

\section{Complications/disadvantages}

The disadvantages of IPCs, as with other interventions, are often subjective and may differ depending on patient values, such as maintaining a completely unrestricted lifestyle or refusal of catheter insertion on the basis of esthetic reasons. IPC-related complications are minor and easily treatable, eg, cellulitis, blockage, catheter malfunction, pleural infection, and fluid loculation. ${ }^{4}$ Pain secondary to catheter placement has been reported in prospective trials; however, when compared to chest-tube thoracostomy and pleurodesis, it is not different initially or over time. ${ }^{4}$ In a multicenter study, Fysh et al showed that IPC-related pleural infections occurred in $<5 \%$ of over 1,000 patients and were usually controlled with appropriate antibiotics. ${ }^{54}$ The risk of mortality from pleural infection was only $0.3 \%$. In the TIME2 trial, serious pleural infection associated with IPCs was reported in more patients than talc pleurodesis (five versus one), with one patient's death attributed to the infection (14\%). Patients with mesothelioma have been 
reported to develop catheter-tract metastases in approximately $10 \%-27 \%$ of those with IPCs in place in retrospective and prospective studies, respectively. The symptoms are generally mild and usually respond to radiotherapy. ${ }^{55,56}$

\section{Combined approaches}

There have been few studies that have explored the combination of therapeutic interventions, most recently involving pleuroscopic pleurodesis and IPCs. Reddy et al first reported using this approach, wherein they evaluated the safety, efficacy, and feasibility of a rapid pleurodesis protocol by performing medical thoracoscopy followed by tunneled pleural catheter placement and talc poudrage in 30 individuals. Dyspnea and quality of life improved in all patients. In addition, median duration in hospital was 1.79 days following the procedure, with successful pleurodesis in $92 \%$ of individuals. The tunneled pleural catheter was removed at a median of 7.54 days, and complications included fever, TPC replacement, and empyema in two, one, and one patients, respectively. ${ }^{57}$ Another observational study by Boujaoude et al reported outcomes of pleuroscopic pleurodesis followed by tunneled pleural catheter against a previously treated cohort of patients using conventional pleuroscopic pleurodesis. ${ }^{58}$ The authors reported successful pleurodesis in $92 \%$ of patients, improved dyspnea, and median length of stay of 3 days compared with 9 days in the conventional-pleurodesis group. Ahmed et al reported a case series of patients with MPE receiving talc pleurodesis through IPCs. Successful pleurodesis was seen in $92 \%$ of patients in this series, with few complications. ${ }^{59}$ The IPCPLUS trial is the first randomized controlled trial evaluating the effect of IPCs plus talc pleurodesis compared with IPCs alone, and the results of this trial are pending. ${ }^{60}$

\section{Comparative effectiveness}

A Cochrane review and network meta-analysis by Clive et al was recently published that analyzed both direct and indirect evidence regarding the overall effectiveness of the various management options in terms of pleurodesis efficacy as a primary outcome and dyspnea, quality of life, fever and pain, hospital stay, mortality, and costs as secondary outcomes. ${ }^{34}$ Table 1 highlights some of the major conclusions of this comprehensive network analysis.

\section{Challenges \\ What are the important patient outcomes?}

Historically, successful management of MPE focused on adequate drainage of the hemithorax. Fortunately, research studies and clinical practice have evolved to consider more patient-centered outcomes as the main focus of determining whether particular treatments are effective. Important patientrelated issues influencing management of MPE include How do we identify those patients who will benefit from drainage?; How do we predict who will have recurrence of pleural fluid and hence may benefit from pleurodesis or IPC?; Are there clinical or biological factors that can help us predict who will live long enough to warrant more definitive management with pleurodesis or IPC?; and lastly, How do we minimize days in hospital?

\section{How do we identify those who will benefit from drainage?}

To date, this has been largely determined by patient symptoms, most commonly dyspnea. There have been a few algorithms proposed for managing MPE, and all have recommended various intervention strategies in the presence of symptoms and observation for patients without symptoms. ${ }^{44,65}$

Tunneled pleural catheters are especially helpful in the management of trapped lung in the setting of an MPE and can be considered first-line therapy for those patients who derive benefit from fluid removal. ${ }^{66-68}$ Trapped lung may often be identified by the absence of lung reexpansion postthoracentesis. In addition, the measurement of pleural manometry can be very helpful in diagnosing trapped lung: an initial pleural pressure below $-10 \mathrm{~cm} \mathrm{H}_{2} \mathrm{O}$ or if the pleural pressure falls more than $20 \mathrm{~cm} \mathrm{H}_{2} \mathrm{O}$ per $1,000 \mathrm{~mL}$ of fluid removed in the absence of bronchial obstruction is suggestive. ${ }^{69}$ Pleural ultrasound using M-Mode and speckle-tracking imaging of the cardiac impulse's effect on strain and total movement of the atelectatic lobe may also be helpful in identifying those patients with trapped lung before an invasive procedure. ${ }^{70}$

\section{How do we predict who will have recurrence of pleural fluid?}

The overall probability of pleural fluid reaccumulation is high in MPE, and as a result there are some who advocate for definitive intervention in all cases of MPE. However, reaccumulation is not a certainty and all procedures carry some risk, so there has been ongoing interest in accurately predicting which patients might experience recurrence of fluid. The role of patient-reported outcomes (dyspnea) in predicting fluid recurrence has been explored by one group. ${ }^{71}$ A group of 64 patients were asked to complete the modified Borg Scale and visual analog scale regarding their dyspnea symptoms at rest and with exercise (49 completed questionnaires). Those with higher increase in modified Borg Scale 
Table I Summary of Cochrane-review network meta-analysis of MPE-management therapies

\begin{tabular}{l} 
Primary outcome \\
\hline Pleurodesis efficacy \\
*OR >I indicates higher \\
probability of pleurodesis \\
failure relative to \\
comparator
\end{tabular}

Secondary outcomes Breathlessness

Pain

$* O R<I$ indicates lower probability of pain relative to comparator

Quality of life

Fever

*Higher rank most likely to be associated with fever

Takeaway points
Talc poudrage ranked highest among all pleurodesis agents (rank
2 of 16 methods).\#

Placebo ranked lowest among all pleurodesis agents (rank 15 of 16 methods).

Talc poudrage vs following agents:

- bleomycin, OR 9.7 (2.I-44.78)*

- tetracycline, OR I2.I (I.32-III.3)*

- talc slurry, OR I.3I (0.92-I.85)*

Bleomycin versus tetracycline:

- tetracycline, OR 2 ( I.07-3.75)*

IPC versus talc slurry:

- IPC OR 3.35 (I.64-6.83)*

Eleven studies reported on breathlessness using a number of measures, including MRC, VAS scores, dyspnea index, QLQ-C30/ $\mathrm{LCI}$, functional class, general scale 0-10.

IPC showed improved dyspnea compared with talc slurry at 6 months, but no difference at 42 days using VAS scores. ${ }^{4}$ Another study reported improved dyspnea with IPC compared to talc slurry at 30 days using dyspnea scores. ${ }^{5}$ IPC was associated with improved breathlessness (but lower pleurodesis success rates). Bleomycin was associated with improved dyspnea compared with doxycycline at 2 months.

Mitoxantrone was associated with improved dyspnea over mepacrine.

Six studies reporting on breathlessness found no difference between groups.

There was no evidence of difference in pain among most of the therapeutic methods in both the network meta-analysis of studies and studies that were excluded from the network meta-analysis.

Doxycycline versus $C$. parvum:

- doxycycline OR 0.I (0.01, 0.96)

Many studies did not report pain related to the procedure.

Fifteen studies reported on quality of life or symptoms other than dyspnea using various scales: Karnofsky performance scale,

QLQ-C30, SF-36, WHOQOL-Bref scale, EQ5D, VAS score, a symptom questionnaire, and numeric pain scale.

Seven studies reported evidence of difference between treatment groups:

- improved tiredness with mitoxantrone used over mepacrine ${ }^{61}$

- improved fatigue in talc poudrage use over talc slurry ${ }^{35}$

- improved EQ5D scores at 6 months over talc group, but no difference in QLQ-C30 scores $^{37}$

- improved performance scores at I week for patients receiving LC90I862 than those who did not; improved performance scores at 6 weeks with cisplatin and Ad-p53 versus cisplatin alone $^{63}$

- improved Karnofsky performance score with bevacizumab and cisplatin versus cisplatin alone ${ }^{64}$

Placebo was associated with the least fever.

C. parvum and mepacrine were associated with the most fever, ranked II and 10, respectively, followed by bleomycin, talc slurry, and talc poudrage in descending order.*

There was large variation and overlap in the estimates of fever among the various pleurodesis methods.

Studies, $\mathbf{n} \quad$ Type of comparison

Direct

$n=2$
$n=1$
$n=5$
$n=2$
$n=11$
$n=2$
$n=1$
$n=1$
$n$
$n=6$

$\mathrm{n}=\mathrm{I}(4 \mathrm{I}$ subjects)

$\mathrm{n}=15$

$\mathrm{n}=30$ (subjects)

$\mathrm{n}=50$ I (subjects)

$\mathrm{n}=196$ (subjects -

mesothelioma)

$\mathrm{n}=95$ (subjects)

$\mathrm{n}=35$ (subjects)

$\mathrm{n}=2$

$\mathrm{n}=5, \mathrm{n}=3$ studies,

respectively
Direct and indirect

Direct and indirect

ran

(Continued) 
Table I (Continued)

\begin{tabular}{|c|c|c|c|}
\hline Primary outcome & Takeaway points & Studies, $\mathbf{n}$ & Type of comparison \\
\hline \multirow[t]{7}{*}{ Mortality } & 34 trials provided data on mortality. & & Direct and indirect \\
\hline & Two trials reported differences between treatment arms. & & \\
\hline & Thoracoscopic tetracycline pleurodesis was associated with & $\mathrm{n}=1$ study & \\
\hline & longer survival than bedside administration of tetracycline. & (34 subjects) & \\
\hline & In a study evaluating bleomycin compared to IFN, those receiving & $\mathrm{n}=\mathrm{I}$ study & \\
\hline & bleomycin appeared to live longer: OR for death $0.46(0.25-0.87)$ & (160 subjects) & \\
\hline & Overall, there was no evidence of difference in ranking among the & & \\
\hline \multirow[t]{12}{*}{ Length of stay } & Sixteen of 62 studies reported length of stay. & & \\
\hline & Many reported no evidence of significant difference between & & \\
\hline & groups. & & \\
\hline & A few individual studies reported differences in length of stay, & & \\
\hline & based on: & & \\
\hline & - drainage time prior to administration of agent (rapid drainage & & \\
\hline & vs standard care) & & \\
\hline & - drainage removal after administration (early vs standard care) & & \\
\hline & - talc pleurodesis versus VATS partial pleurectomy & & \\
\hline & - talc-slurry pleurodesis versus mechanical pleurodesis & & \\
\hline & - iodine versus talc poudrage & & \\
\hline & - IPC versus talc slurry pleurodesis & & \\
\hline \multirow[t]{5}{*}{ Costs } & Rapid pleurodesis was cheaper than standard care. & $n=1$ & \\
\hline & Talc slurry was cheaper than bleomycin. & $n=3$ & \\
\hline & Talc poudrage was cheaper than bleomycin. & $n=1$ & \\
\hline & VATS pleurectomy was more expensive than talc pleurodesis. & $n=1$ & \\
\hline & $\begin{array}{l}\text { No difference was found between talc slurry versus talc } \\
\text { poudrage. }\end{array}$ & $n=1$ & \\
\hline
\end{tabular}

Notes: "Ranks given are median estimated ranks for each agent, with $95 \%$ credible intervals to reflect the degree of uncertainty around the rank. As a result, there may be more than one intervention per rank. Data from Clive et $\mathrm{al}^{34}$

Abbreviations: MPE, malignant pleural effusion; OR, odds ratio; IPC, indwelling pleural catheter; MRC, Medical Research Council; VAS, visual analog scale; C. parvum, Cryptosporidium parvum; QLQ, Quality of Life Questionnaire; SF, Short Form (Health Survey); WHOQOL, World Health Organization Quality of Life; EQ, EuroQol; VATS, video-assisted thoracoscopic surgery.

scores with exercise and those who required large-volume drainage initially were factors associated with reintervention.

Another multicenter study of consecutive patients with first thoracentesis analyzed them retrospectively for risk factors for PE recurrence. ${ }^{72}$ Patients with large effusions on initial chest radiograph, as well as those with chemotherapy within 30 days after thoracentesis, had high probability of fluid recurrence, whereas those with lymphoma and chemotherapy within 30 days prior to thoracentesis had low probability of fluid recurrence.

\section{How do we predict who will live long enough to warrant more definitive management with pleurodesis or IPCs? \\ Tumor type}

Anevlavis et al studied prognostic factors, including cancer type, in patients initially presenting with undiagnosed PE proven to be malignant by diagnostic thoracoscopy. Patients with lymphoma had the best median survival (26 months), while patients with ovarian and breast carcinomas had the second-best survival (18 and 15 months, respectively), followed by gastrointestinal, head and neck, and genitourinary cancers. Patients with non-small cell lung cancer and small-cell lung cancer had survival times of 9.5 and 6 months, respectively, while mesothelioma patients in this study had an 8 -month survival time. ${ }^{73}$ Another study by Clive et al evaluated prognostic factors associated with MPE and found tumor type, among a few other factors, to influence survival. ${ }^{19}$ In this retrospective analysis of three data sets, mesothelioma was associated with the longest median survival (339 days), followed by hematological malignancy (218 days), gynecological malignancy, and breast cancer (203 and 192 days, respectively), with the worst survival seen in urological cancers ( 33 days) followed by sarcoma and melanoma (44 and 43 days, respectively). Lung cancer was associated with a median survival of 74 days. In patients with triple-negative breast cancer who test positive for malignant cells in the pleural fluid, the prognosis is poor and survival reduced. ${ }^{74}$

\section{Inflammatory markers}

There have been numerous studies evaluating the association between serum and/or pleural markers in determining 
prognosis of patients with MPE, and results have been mixed for most markers. Pleural $\mathrm{pH}$ has had mixed results reported about its ability to predict survival in patients. ${ }^{75-77}$ In a retrospective study of 68 patients with lung cancer and MPE, high pleural CRP level was an independent prognostic factor associated with poor survival time. ${ }^{78}$

Survivin is an inhibitor of apoptosis, is selectively upregulated in certain tumors, and has been correlated with poor outcomes. In a study by Görgün et al, ${ }^{79}$ survivin levels below a level of $20 \mathrm{pg} / \mathrm{mL}$ was predictive of poor survival (median survival 75 days) compared with levels above 20 $\mathrm{pg} / \mathrm{mL}$ (median survival 219 days).

A recent study evaluated a combination of serum and pleural markers in two groups of patients with MPE stratified by survival time less than and greater than 30 days. ${ }^{80}$ Predictors of 30-day mortality included tumor type, specifically primary lung and gastrointestinal cancers, pleural protein levels $<3.6 \mathrm{~g} / \mathrm{dL}$, hemoglobin $<11 \mathrm{~g} / \mathrm{dL}$, and serum leukocytes $>9 \times 10^{9} / \mathrm{L}$. In this study, increased leukocytes were predictive of 30-day mortality in multivariate analysis. This is in contrast to another study by Anevlavis et al, which found that increased neutrophil:lymphocyte ratio (NLR) but not increased leukocytes in the blood was associated with poor survival. ${ }^{81}$

PS

Patient PS has been previously correlated with survival. ${ }^{82}$ Yoon et al looked at the prognosis of patients following VATS talc pleurodesis over a 2-year period and found that poor PS (Eastern Cooperative Oncology Group [ECOG] 3 or 4) and prior chemotherapy or radiotherapy was predictive of reduced overall survival. ${ }^{83}$

In the TIME2 randomized trial, 36 of 100 patients died within 3 months of trial enrollment, despite the exclusion criteria for the trial being survival $<3$ months and ECOG PS being used to inform this decision. ${ }^{4}$ There have been other studies which have evaluated the combination of PS with other clinical and laboratory data to improve this prediction. A study of 90 patients diagnosed with MPE using thoracoscopy found that tumor histology, PS, and NLR >3 were associated with poor survival. ${ }^{81}$ The authors did not find any difference in survival according to pleural $\mathrm{pH}$ level, glucose, or protein levels. Patients with ECOG PS 0 had the best median survival (24 months), while patients with a score of 1,2 , or 3 had median survival of 9,5 , or 1.5 months, respectively.

\section{Predictive scores}

Clive et al completed the largest work to date by combining three datasets comprising 789 patients, whereby they identified 14 predefined variables recorded at the time of MPE diagnosis and evaluated their impact on survival. ${ }^{19}$ Multivariate analysis using backward selection identified six variables independently associated with survival: effusion size, ECOG PS, pleural fluid lactate dehydrogenase (LDH), serum NLR, serum N-terminal pro-brain natriuretic peptide, and malignant cell type. Four variables were chosen based on clinical applicability and a prognostic scoring (named LENT score [LDH, ECOG PS, NLR, tumor type]; score range 0-7) system was developed, which was then fully validated. Patients with moderate-risk and high-risk LENT scores had hazard ratios (95\% CI) for mortality of 1.49 (1.03-2.15) and 5.97 (3.58-9.97) compared with those with a low-risk LENT score. The LENT score also outperformed PS alone in terms of predicting prognosis. Table 2 summarizes the proportion of patients surviving 1,3 , and 6 months according to LENT prognostic score.

\section{Which interventions minimize days in hospital overall?}

Given the limited survival in many patients with MPE, reducing days spent in hospital is considered an important factor in patient-related outcomes. A relevant issue in this regard not only considers the potential for outpatient management versus inpatient management at the time of intervention, but

Table 2 Proportion of patients surviving to I, 3, and 6 months according to LENT prognostic score

\begin{tabular}{lllll}
\hline $\begin{array}{l}\text { LENT prognostic } \\
\text { score }\end{array}$ & $\begin{array}{l}\text { Median survival, } \\
\text { days (IQR) }\end{array}$ & \multicolumn{2}{l}{ Probability of survival (\%) } \\
\cline { 3 - 5 } & At I month & At 3 months & At 6 months \\
\hline Cohort I, $\mathbf{n = 2 0 3}$ & $319(228-549)$ & 100 & 98 & 86 \\
Low risk (0-I) & $130(47-467)$ & 81 & 59 & 47 \\
Moderate risk (2-4) & $44(22-77)$ & 65 & 13 & 3 \\
High risk (5-7) & & & & \\
Cohort 2, $\mathbf{n}=\mathbf{7 6}$ & & 100 & 100 & 92 \\
Low risk (0-I) & & 93 & 65 & 57 \\
Moderate (2-4) & 72 & 33 & 17 \\
High (5-7) & & 72 & \\
\hline
\end{tabular}

Note: Data from Clive et al ${ }^{19}$

Abbreviation: IQR, interquartile range. 
probably more importantly the potential for adverse events or treatment failure that may necessitate hospitalization to manage it. This is particularly important in a population of patients with a terminal disease and limited life expectancy. Of the various therapeutic options, simple thoracentesis and IPCs are for the most part outpatient procedures with no associated hospitalization. There have been a few clinical trials that prospectively document hospitalization time for patients and specifically compare IPCs to talc pleurodesis., ${ }^{432,84}$

In a costing analysis performed alongside the TIME2 trial, ${ }^{85}$ mean length of stay at the time of intervention was less in the IPC group than the talc-pleurodesis group (2.49 days versus 4.98 days, respectively; median 0 days versus 4 days). During the trial, a total of 28 adverse events were reported in the IPC group and nine in the talc-pleurodesis group. In the IPC group, these resulted in 33 outpatient visits (among 17 individuals) and 15 admissions to hospital (among 11 individuals), with an average length of stay of 8.86 (standard deviation 12) days. In the talc-pleurodesis group, there were 41 additional outpatient visits (among 12 individuals) and 15 admissions to hospital (among 10 individuals), with an average length of stay of 5.46 (standard deviation 4) days.

In the AMPLE trial, a multinational randomized trial evaluating IPCs versus talc pleurodesis in Australia and Asia, total hospitalization days and PE-related hospital days were captured over a 12-month period. Total hospitalization days were lower in the IPC group $(n=73)$, with a median of 10 versus 12 days in the talc-pleurodesis group. Mean difference in hospitalization days between the groups was 3.7 days/patient (12.7 IPC vs 16.3 talc pleurodesis), and the IPC group had fewer effusion-related days in hospital (median 1 vs 4 days). ${ }^{32}$

Another 12-month multicenter study of patient-determined treatment of MPE compared total and PE-related hospital days between IPC and talc pleurodesis. ${ }^{84}$ In this study, total and PE-related hospital days were fewer in the IPC group (median 6.5 and 3 days, respectively) than in the talc-pleurodesis group (median 18 and 10 days, respectively).

\section{What is the best value for money?}

There has been a growth in clinical trials and studies related to managing patients with PE. Choice of therapy for a patient is influenced by many factors, the most crucial being therapy effectiveness. From a health care system point of view, an additional consideration is cost-effectiveness or value of money spent on an intervention. Determining value for money (cost-effectiveness) of an intervention can be done using clinical trial data, if available. More commonly, costs and effectiveness of multiple interventions are compared using a combination of direct or indirect data on relative costs and effectiveness through decision modeling. There have been few studies that have evaluated cost-effectiveness of various management strategies for MPE (Table 3). There has been one economic analysis alongside a clinical trial evaluating IPC versus pleurodesis and thoracoscopy ${ }^{86}$ and a few conducted using decision modeling. ${ }^{87,88}$

The first cost-effectiveness analysis evaluating management options in MPE was published in 2010, evaluating simple thoracentesis, bedside pleurodesis, and IPCs. ${ }^{87}$ Treatment with talc pleurodesis was less costly and slightly more effective overall compared with IPCs. IPCs became cost-effective with an incremental cost-effectiveness ratio less than US\$100,000/quality-adjusted life year (QALY) in patients with survival less than 6 weeks.

An analysis by Puri et al published in 2012 evaluated the costs and quality of life of repeat thoracentesis, IPCs, bedside pleurodesis, and thoracoscopic pleurodesis. ${ }^{88}$ The most cost-effective treatment option changed depending on patient survival. For patients with survival less than 3 months, IPCs were the most effective treatment strategy. However, in this analysis, when patient survival was modeled to 12 months, the most cost-effective option was bedside pleurodesis.

The only cost-effectiveness analysis of IPC versus talc pleurodesis performed alongside a clinical trial was recently published. ${ }^{86}$ Based on the trial population recruited in the TIME2 trial, IPCs were compared with talc pleurodesis in terms of dyspnea, quality of life, and costs. On average, the incremental cost-effectiveness of IPC compared with bedside talc pleurodesis was $\$ 10,870 /$ QALY. At a threshold of $£ 30,000$ (equivalent to approximately $\$ 43,000$ ) per QALY, the probability that IPCs were cost-effective compared to talc was approximately $65 \%$. When treatment was compared in patients with limited survival (less than 14 weeks), at a willingnessto-pay threshold of $£ 30,000(\$ 43,000)$ per QALY, IPCs were cost-effective compared to talc pleurodesis approximately $95 \%$ of the time. In the TIME2 clinical trial, patients and family members performed as-needed drainage of the IPC. In sensitivity analysis assuming additional nursing support required for patients with IPCs to assist with intermittent drainage, the incremental cost-effectiveness ratio increased to $\$ 77,213 /$ QALY and the probability that IPCs were costeffective compared with talc pleurodesis fell to $35 \%$.

Finally, the most recent cost-effectiveness analysis evaluating five possible management strategies for MPE published in 2015, including a rapid-pleurodesis protocol, concluded that IPCs were the most cost-effective alternative to repeat thoracentesis for patients over a 6-month time period. ${ }^{89}$ Their analysis did not explore whether the cost-effectiveness of the 
Table 3 Summary of health economic studies evaluating treatment for MPE

\begin{tabular}{|c|c|c|c|c|c|}
\hline Study & $\begin{array}{l}\text { Economic } \\
\text { analysis } \\
\text { method }\end{array}$ & $\begin{array}{l}\text { Interventions } \\
\text { compared (n) }\end{array}$ & $\begin{array}{l}\text { Outcomes } \\
\text { reported, } \\
\text { currency }\end{array}$ & $\begin{array}{l}\text { Time } \\
\text { frame }\end{array}$ & Results \\
\hline $\begin{array}{l}\text { Olden and } \\
\text { Holloway }\end{array}$ & $\begin{array}{l}\text { Decision } \\
\text { model using } \\
\text { observational } \\
\text { data }\end{array}$ & $\begin{array}{l}\text { Thoracentesis, } \\
\text { bedside } \\
\text { pleurodesis, IPC (3) }\end{array}$ & $\begin{array}{l}\text { Cost-effectiveness } \\
\text { ratio (US\$/QALY) }\end{array}$ & 6 months & $\begin{array}{l}\text { Base-case estimate: talc marginally less expensive, and } \\
\text { no significant difference in QALY. } \\
\text { Conclusion: no difference at } 6 \text { months between } \\
\text { therapies. If survival less than } 6 \text { weeks, IPC may be } \\
\text { more cost-effective than talc. }\end{array}$ \\
\hline Puri et al ${ }^{88}$ & $\begin{array}{l}\text { Decision } \\
\text { model using } \\
\text { observational } \\
\text { data }\end{array}$ & $\begin{array}{l}\text { Thoracentesis, } \\
\text { bedside } \\
\text { pleurodesis, } \\
\text { thoracoscopic } \\
\text { pleurodesis (3) }\end{array}$ & $\begin{array}{l}\text { Cost-effectiveness } \\
\text { ratio (US\$/QALY) }\end{array}$ & I year & $\begin{array}{l}\text { Conclusion: depended on survival. If } \\
\text { survival }<3 \text { months, IPC most cost-effective: } \\
\text { ICER }=\$ 49,978 / Q A L Y \text {. If survival } 12 \text { months or } \\
\text { longer, bedside pleurodesis dominated all treatment } \\
\text { strategies. }\end{array}$ \\
\hline Olfert et $\mathrm{al}^{86}$ & $\begin{array}{l}\text { Clinical trial } \\
\text { data* }\end{array}$ & $\begin{array}{l}\text { Talc pleurodesis, } \\
\text { IPC (2) }\end{array}$ & $\begin{array}{l}\text { Cost-effectiveness } \\
\text { ratio (US\$/ } \\
\text { QALY), costs } \\
\text { converted from } \\
\text { UK£ }\end{array}$ & I year & $\begin{array}{l}\text { Conclusion: mean costs and QALYs between } \\
\text { groups were not significantly different. } \\
\text { ICER }=\$ 10,870 / Q A L Y \text {. Probability that IPC more } \\
\text { cost-effective than talc was } 65 \% \text {. If survival }<\text { I } 4 \text { weeks, } \\
\text { mean costs of IPC significantly less than talc. } \\
\text { Probability that IPC was more cost-effective than talc } \\
\text { was } 95 \% \text {. If all patients with IPC require nursing care } \\
\geq 2 \text { hours/week, then probability that IPC is more } \\
\text { cost-effective than talc falls to } 35 \% \text {. }\end{array}$ \\
\hline Shafiq et $a^{89}$ & $\begin{array}{l}\text { Decision } \\
\text { model using } \\
\text { observational } \\
\text { data and clinical } \\
\text { trial* }\end{array}$ & $\begin{array}{l}\text { Thoracentesis, } \\
\text { talc pleurodesis, } \\
\text { thoracoscopic } \\
\text { pleurodesis with } \\
\text { talc poudrage, IPC, } \\
\text { rapid pleurodesis } \\
\text { protocol (5) }\end{array}$ & $\begin{array}{l}\text { Cost-effectiveness } \\
\text { ratio (US\$/QALY) }\end{array}$ & 6 months & $\begin{array}{l}\text { Repeat thoracentesis was least expensive option, } \\
\text { followed by IPC and talc slurry. IPC was more } \\
\text { effective than repeat thoracentesis, and talc } \\
\text { slurry was slightly more effective than IPC. Both } \\
\text { IPC and TS were considered dominant over talc } \\
\text { poudrage and rapid pleurodesis protocol (less } \\
\text { costly, more effective). ICER (IPC over repeat } \\
\text { thoracentesis) }=\$ 45,747 / \text { QLLY }\end{array}$ \\
\hline
\end{tabular}

Note: *TIME2 clinical trial.

Abbreviations: MPE, malignant pleural effusion; IPC, indwelling pleural catheter; QALY, quality-adjusted life year; ICER, incremental cost-effectiveness ratio; TS, thoracoscopic surgery.

various treatment strategies would change for patients with different survival times.

Overall, based on the health economic analyses performed to date comparing a range of treatment options, repeat thoracentesis would appear the least costly of all treatment strategies, but with the least effectiveness in terms of quality of life. IPCs appear to be a cost-effective strategy compared with all other treatment strategies, particularly when patient survival is limited (less than or equal to 6 months). Based on sensitivity analysis in the economic analysis performed alongside the TIME2 trial, the cost-effectiveness of IPCs, however, becomes much less favorable when nursing care of 2 hours or more is required for IPC drainage on a weekly basis. This variation in cost-effectiveness suggests that regional differences in delivery models of IPC services might impact the true "value for money" spent on IPC management in different jurisdictions and ultimately a decision maker's willingness to pay for it.

\section{Future work}

Although not discussed in this review, the study of the molecular biology of MPE and the role of biomarkers in MPE diagnosis and prognosis have been growing in recent years and have been reviewed recently. ${ }^{90}$ Improved understanding of the molecular causes of MPE and underlying malignancies should promote clinical studies of targeted therapies against MPE in the near future. With the increased use of IPCs allowing long-term outpatient access to the pleural cavity, this makes them an ideal potential portal for local drug delivery. ${ }^{90}$ In addition to IPC-delivered bacterial moieties that have been evaluated as potential immunomodulators against MPE, ${ }^{11,92}$ a number of agents are currently under development and the results are eagerly awaited. To date, there have been no pleural-based interventions that have been found to prolong survival in patients with MPE; however, as new molecules are studied prospectively and survival of patients followed, this important clinical outcome will be able to inform clinical practice.

Successful treatment of MPE represents an ongoing challenge in clinical practice. Recent scientific progress has shed light on the biological processes leading the mechanisms behind the pathobiology of MPE. ${ }^{90}$ Development of novel, effective, biological treatment for patients is impaired by our incomplete 
understanding of basic aspects of cancer metastasis to the pleural space and effusion development. For example, recent studies suggest that tumor cells metastasizing to the pleural space constitute a population disparate to the primary cancer, as evidenced by the significant discordance in $E G F R$-mutation status between the primary tumor and cancer cells in the effusion. ${ }^{93}$

Many therapeutic interventions targeting angiogenesis and vascular permeability have been undertaken against experimental MPE. Blockade of VEGF signaling by either antibodies (bevacizumab) or inhibitors (ZD6474, vandetanib) has been tested experimentally. ${ }^{94,95}$ A recent Phase II clinical trial showed that the addition of bevacizumab to carboplatin-pemetrexed chemotherapy for non-small-cell lung cancer resulted in MPE control without pleurodesis. ${ }^{96}$ Additionally, cancer immunotherapy, the concept of stimulating the innate immune response against cancer cells, has been tested in previous clinical trials with promising results. Intrapleural administration of IL2 has been addressed in Phase I clinical studies with encouraging results, which warrant further clinical investigation. ${ }^{97}$

To date there have been few studies that have incorporated important costs and benefits of therapies into clinical trials evaluating MPE-treatment strategies. Specifically, incorporation of patient and caregiver time associated with treatment of MPE (eg, lost wages due to hospitalization or ongoing IPC drainage) have not been included in the health economic analysis of MPE therapies to date, but are arguably vital "costs" to patients and society that should be considered when evaluating the overall cost-effectiveness of MPE therapies. Upfront incorporation and measurement of relevant health economic variables alongside clinical trials will improve our understanding of the value of different therapies for MPE and the impact of therapies on subgroups of patients with MPE. This will require collaboration among clinicians and health economists early in the clinical trial-design process and careful thought about handling generalizability of results and treatment recommendations among different health systems and countries.

\section{Conclusion}

The choice of therapy for a patient with MPE is influenced by many factors, the most crucial being a therapy's effectiveness. Given the limited resources faced by almost every health system, cost and cost-effectiveness have become major considerations when considering adoption of new therapeutic options. The management options available to patients with MPE have increased in the past decade, and there have been a growing number of prospective studies demonstrating the comparative effectiveness of these therapies in terms of important patient outcomes. The challenge for clinicians and patients deciding on the preferred-treatment strategy is that the therapies available to patients vary appreciably in terms of procedure placement (inpatient versus outpatient), risks, and complications. Furthermore, clinicians have been limited in terms of accurately predicting who may benefit from either pleurodesis or IPCs. Routine use of prediction scores in clinical practice has the potential to help in discussions with patients about prognosis and ultimately guide the choice of therapy.

\section{Disclosure}

The authors report no conflicts of interest in this work.

\section{References}

1. Taghizadeh N, Fortin M, Tremblay A. USA hospitalizations for malignant pleural effusions: data from the 2012 National Inpatient Sample. Chest. Epub 2016 Nov 19.

2. American Thoracic Society. Management of malignant pleural effusions Am J Respir Crit Care Med. 2000;162:1987-2001.

3. Bennett R, Maskell N. Management of malignant pleural effusions. Curr Opin Pulm Med. 2005;11:296-300.

4. Davies HE, Mishra EK, Kahan BC, et al. Effect of an indwelling pleural catheter vs chest tube and talc pleurodesis for relieving dyspnea in patients with malignant pleural effusion: the TIME2 randomized controlled trial. JAMA. 2012;307:2383-2389.

5. Demmy TL, Gu L, Burkhalter JE, et al. Optimal management of malignant pleural effusions (results of CALGB 30102). J Natl Compr Canc Netw. 2012;10(8):975-982.

6. Antunes G, Neville E, Duffy J, Ali N. BTS guidelines for the management of malignant pleural effusions. Thorax. 2003;58 (Suppl 2): ii29-ii38.

7. Simoff MJ, Lally B, Slade MG, et al. Symptom management in patients with lung cancer - diagnosis and management of lung cancer, 3rd ed: American College of Chest Physicians evidence-based clinical practice guidelines. Chest. 2013;143:e455S-e497S.

8. Sahn SA. Pleural diseases related to metastatic malignancies. Eur Respir J. 1997;10:1907-1901.

9. Sahn SA. Malignancy metastatic to the pleura. Clin Chest Med. 1998;19:351-361.

10. Apffelstaedt JP, Van Zyl JA, Muller AG. Breast cancer complicated by pleural effusion. J Surg Oncol. 1995;58:173-175.

11. Kreisman H, Wolkove N, Finkelstein HS, Cohen C, Margolese R, Frank H. Breast cancer and thoracic metastasis: review of 119 patients. Thorax. 1983;38:175-179.

12. Weichselbaum R, Marck A, Hellman S. Pathogenesis of pleural effusion in carcinoma of the breast. Int J Radiat Oncol Biol Phys. 1977;2:963-965.

13. Chernow B, Sahn SA. Carcinomatous involvement of the pleura: an analysis of 96 patients. Am J Med. 1977;63:695-702.

14. Hsu C. Cytologic detection of malignancy in pleural effusion: a review of 5,255 samples from 3,811 patients. Diagn Cytopathol. 1987;3:8-12.

15. Johnston WW. The malignant pleural effusion: a review of cytopathologic diagnoses of 584 specimens from 472 consecutive patients. Cancer. 1985;56:905-909.

16. Salyer WR, Eggleston JC, Erozan YS. Efficacy of pleural needle biopsy and pleural fluid cytopathology in the diagnosis of malignant neoplasm involving the pleura. Chest. 1975;67:536-9.

17. Sears D, Hajdu SI. The cytologic diagnosis of malignant neoplasms in pleural and peritoneal effusions. Acta Cytol. 1987;31:85-97.

18. Heffner JE, Nietert PJ, Barbieri C. Pleural fluid $\mathrm{pH}$ as a predictor of survival for patients with malignant pleural effusions. Chest. 2000;117:79-86. 
19. Clive AO, Kahan BC, Hooper CE, et al. Predicting survival in malignant pleural effusion: development and validation of the LENT prognostic score. Thorax. 2014;69:1098-1104.

20. Livingston RB, McCracken JD, Trauth CJ, Chen T. Isolated pleural effusion in small cell lung carcinoma: favorable prognosis. Chest. 1982;81:208-210.

21. Das DK. Serous effusions in malignant lymphomas: a review. Diagn Cytopathol. 2006;34:335-347.

22. Sahn SA. State of the art: the pleura. Am Rev Respir Dis. 1988;138:184-234.

23. Meyer PC. Metastatic carcinoma of the pleura. Thorax. 1966;21:437-443.

24. Rodriguez-Panadero F, Borderas Naranjo F, Lopez-Mejias J. Pleural metastatic tumours and effusions: frequency and pathogenic mechanisms in a post-mortem series. Eur Respir J. 1989;2:366-369.

25. Shannon VR, Eapen GA, Jimenez CA, et al. Respiratory complications. In: Kufe DW, Bast RC Jr, Hait W, et al, editors. Cancer Medicine. 7th ed. Philadelphia: BC Decker; 2006:2150-2173.

26. Stathopoulos GT, Kalomenidis I. Malignant pleural effusion: tumor-host interactions unleashed. Am J Respir Crit Care Med. 2012;186:487-492.

27. Stathopoulos GT, Psallidas I, Moustaki A, et al. A central role for tumor-derived monocyte chemoattractant protein-1 in malignant pleural effusion. J Natl Cancer Inst. 2008;100:1464-1476.

28. Psallidas I, Stathopoulos GT, Maniatis NA, et al. Secreted phosphoprotein-1 directly provokes vascular leakage to foster malignant pleural effusion. Oncogene. 2013;32:528-535.

29. Martinez-Moragon E, Aparicio J, Sanchis J, Menendez R, Rogado MC, Sanchis F. Malignant pleural effusion: prognostic factors for survival and response to chemical pleurodesis in a series of 120 cases. Respiration. 1998;65:108-113.

30. Tammilehto L, Maasilita P, Kostianen S, Appelqvist P, Holsti LR, Mattson K. Diagnosis and prognostic factors in malignant pleural mesothelioma: a retrospective analysis of sixty-five patients. Respiration. 1992; 52:129-135.

31. Tammilehto L. Malignant mesothelioma: prognostic factors in a prospective study of 98 patients. Lung Cancer. 1992;8:175-184.

32. Fysh ET, Thomas R, Smith NA, et al. Australasian Malignant Pleural Effusion (AMPLE) trial: a multicentre randomised study comparing indwelling pleural catheter versus talc pleurodesis. Poster presented at: ATS International Conference; May 13-18, 2016; San Francisco, CA.

33. Putnam JB Jr, Light RW, Rodriguez RM, et al. A randomized comparison of indwelling pleural catheter and doxycycline pleurodesis in the management of malignant pleural effusions. Cancer. 1999;86:1992-1999.

34. Clive AO, Jones HE, Bhatnagar R, et al. Interventions for the management of malignant pleural effusions: a network meta-analysis. Cochrane Database Syst Rev. 2016:CD010529.

35. Dresler CM, Olak J, Herndon JE 2nd, et al. Phase III intergroup study of talc poudrage vs talc slurry sclerosis for malignant pleural effusion. Chest. 2005;127:909-915.

36. Janssen JP, Collier G, Astoul P, et al. Safety of pleurodesis with talc poudrage in malignant pleural effusion: a prospective cohort study. Lancet. 2007;369:1535-1539.

37. Rintoul RC, Ritchie AJ, Edwards JG, et al. Efficacy and cost of videoassisted thoracoscopic partial pleurectomy versus talc pleurodesis in patients with malignant pleural mesothelioma (MesoVATS): an openlabel, randomised, controlled trial. Lancet. 2014;384:1118-1127.

38. Colt HG. Thoracoscopy: a prospective study of safety and outcome. Chest. 1995;108:324-329.

39. Trotter D, Aly A, Siu L, Knight S. Video-assisted thoracoscopic (VATS) pleurodesis for malignant effusion: an Australian teaching hospital's experience. Heart Lung Circ. 2005;14:93-97.

40. Mitrofan C, Aldea A, Grigorescu C, et al. Pleurodeza Toracoscopica in pleureziile maligne. [Thoracoscopic pleurodesis in malignant pleural effusions]. Rev Med Chir Soc Med Nat Iasi. 2005;109:799-803. Romanian.

41. Luh SP, Chen CY, Tzao CY. Malignant pleural effusion treatment outcomes: pleurodesis via video-assisted thoracic surgery (VATS) versus tube thoracostomy. Thorac Cardiovasc Surg. 2006;54:332-336.

42. Cardillo G, Facciolo F, Carbone L, et al. Long-term follow-up of videoassisted talc pleurodesis in malignant recurrent pleural effusions. Eur J Cardiothorac Surg. 2002;21:302-306.
43. Arapis K, Caliandro R, Stern JB, Girard P, Debrosse D, Gossot D. Thoracoscopic palliative treatment of malignant pleural effusions: results in 273 patients. Surg Endosc. 2006;20:919-923.

44. Roberts ME, Neville E, Berrisford RG, Antunes G, Ali NJ. Management of a malignant pleural effusion: British Thoracic Society pleural disease guideline 2010. Thorax. 2010;65 (Suppl 2):ii32-ii40.

45. Wahidi MM, Reddy C, Yarmus L, et al. Randomized trial of pleural fluid drainage frequency in patients with malignant pleural effusions: the ASAP trial. Am J Respir Crit Care Med. Epub 2016 Nov 29.

46. Tremblay A, Michaud G. Single-center experience with 250 tunnelled pleural catheter insertions for malignant pleural effusion. Chest. 2006;129:362-368.

47. Sabur NF, Chee A, Stather DR, et al. The impact of tunneled pleural catheters on the quality of life of patients with malignant pleural effusions. Respiration. 2013;85:36-42.

48. Van Meter ME, McKee KY, Kohlwes RJ. Efficacy and safety of tunneled pleural catheters in adults with malignant pleural effusions: a systematic review. J Gen Intern Med. 2011;26:70-76.

49. Efthymiou CA, Masudi T, Thorpe JA, Papagiannopoulos K. Malignant pleural effusion in the presence of trapped lung: five-year experience of PleurX tunnelled catheters. Interact Cardiovasc Thorac Surg. 2009;9:961-964.

50. Qureshi RA, Collinson SL, Powell RJ, Froeschle PO, Berrisford RG. Management of malignant pleural effusion associated with trapped lung syndrome. Asian Cardiovasc Thorac Ann. 2008;16:120-123.

51. Pien GW, Gant MJ, Washam CL, Sterman DH. Use of an implantable pleural catheter for trapped lung syndrome in patients with malignant pleural effusion. Chest. 2001;119:1641-1646.

52. Srour N, Amjadi K, Forster A, Aaron S. Management of malignant pleural effusions with indwelling pleural catheters or talc pleurodesis. Can Respir J. 2013;20:106-110.

53. Mekhaiel E, Kashyap R, Mullon JJ, Maldonado F. Infections associated with tunnelled indwelling pleural catheters in patients undergoing chemotherapy. J Bronchology Interv Pulmonol. 2013;20:299-303.

54. Fysh ET, Tremblay A, Feller-Kopman D, et al. Clinical outcomes of indwelling pleural catheter-related pleural infections: an international multicenter study. Chest. 2013;144:1597-1602.

55. Thomas R, Budgeon CA, Kuok YJ, et al. Catheter tract metastasis associated with indwelling pleural catheters. Chest. 2014;146:557-562.

56. Clive AO, Taylor H, Dobson L, et al. Prophylactic radiotherapy for the prevention of procedure-tract metastases after surgical and large-bore pleural procedures in malignant pleural mesothelioma (SMART): a multicentre, open-label, phase 3, randomised controlled trial. Lancet Oncol. 2016 17:1094-1104.

57. Reddy C, Ernst A, Lamb C, Feller-Kopman D. Rapid pleurodesis for malignant pleural effusions: a pilot study. Chest. 2011;139:1419-1423.

58. Boujaoude Z, Bartter T, Abboud M, Pratter M, Abouzgheib W. Pleuroscopic pleurodesis combined with tunneled pleural catheter for management of malignant pleural effusion: a prospective observational study. J Bronchology Interv Pulmonol. 2015;22:237-243.

59. Ahmed L, Ip H, Rao D, Patel N, Noorzad F. Talc pleurodesis through indwelling pleural catheters for malignant pleural effusions: retrospective case series of a novel clinical pathway. Chest. 2014;146:e190-e194.

60. Bhatnagar R, Kahan BC, Morley AJ, et al. The efficacy of indwelling pleural catheter placement versus placement plus talc sclerosant in patients with malignant pleural effusions managed exclusively as outpatients (IPC-PLUS):study protocol for a randomised controlled trial. Trials. 2015;16:48.

61. Bjermer L, Gruber A, Sue-Chu M, Sandström T, Eksborg S, Henriksson R. Effects of intrapleural mitoxantrone and mepacrine on malignant pleural effusion: a randomised study. Eur J Cancer. 1995;31:2203-2208.

62. Masuno T, Kishimoto S, Ogura T, et al. A comparative trial of LC 9018 plus doxorubicin and doxorubicin alone for the treatment of malignant pleural effusion secondary to lung cancer. Cancer. 1991;68:1495-1500.

63. Zhao WZ, Wang JK, Li W, Zhang XL. [Clinical research on recombinant human Ad-p53 injection combined with cisplatin in treatment of malignant pleural effusion induced by lung cancer]. Ai Zheng. 2009;28:84-87. Chinese. 
64. Du N, Li X, Li F, et al. Intrapleural combination therapy with bevacizumab and cisplatin for non-small cell lung cancer-mediated malignant pleural effusion. Oncol Rep. 2013;29:2332-2340.

65. Gillen J, Lau C. Permanent indwelling catheters in the management of pleural effusions. Thorac Surg Clin. 2013;23:63-71.

66. Efthymiou CA, Masudi T, Thorpe JA, Papagiannopoulos K. Malignant pleural effusion in the presence of trapped lung: five-year experience of PleurX tunnelled catheters. Interact Cardiovasc Thorac Surg. 2009;9:961-964.

67. Sioris T, Sihvo E, Salo J, Räsänen J, Knuuttila A. Long-term indwelling pleural catheter (PleurX) for malignant pleural effusion unsuitable for talc pleurodesis. Eur J Surg Oncol. 2009;35:546-551.

68. Pien GW, Gant MJ, Washam CL, Sterman DH. Use of an implantable pleural catheter for trapped lung syndrome in patients with malignant pleural effusion. Chest. 2001;119:1641-1646.

69. Light RW, Jenkinson SG, Minh V, et al. Observations on pleural pressures as fluid is withdrawn during thoracentesis. Am Rev Respir Dis. 1980;121:799-804.

70. Salamonsen MR, Lo AK, Ng AC, et al. Novel use of pleural ultrasound can identify malignant entrapped lung prior to effusion drainage. Chest. 2014;146:1286-1293.

71. Boshuizen RC, Vincent AD, van den Heuvel MM. Comparison of modified Borg scale and visual analog scale dyspnea scores in predicting re-intervention after drainage of malignant pleural effusion. Support Care Cancer. 2013;21(11):3109-3116.

72. Grosu HB, Molina S, Casal R, et al. A model to predict pleural effusion recurrence. Poster presented at: American Thoracic Society International Conference; May 13-18, 2016; San Francisco, CA.

73. Anevlavis S, Kouliatsis G, Sotiriou I, et al. Prognostic factors in patients presenting with pleural effusion revealing malignancy. Respiration. 2014;87:311-316.

74. Santos GT, Prolla JC, Camillo ND, Zavalhia LS, Ranzi AD, Bica CG Clinical and pathological factors influencing the survival of breast cancer patients with malignant pleural effusion. J Bras Pneumol. 2012;38:487-493.

75. Sahn SA, Good JT Jr. Pleural fluid $\mathrm{pH}$ in malignant effusions: diagnostic, prognostic, and therapeutic implications. Ann Intern Med. 1988;108:345-349.

76. Rodriguez-Panadero F, Lopez-Mejias J. Survival time of patients with pleural metastatic carcinoma predicted by glucose and $\mathrm{pH}$ studies. Chest. 1989;95:320-324.

77. Foresti V, Scolari N, Villa A, Parisio E, De Filippi G, Guareschi G. Malignant pleural effusions: meaning of pleural-fluid $\mathrm{pH}$ determination. Oncology. 1990;47:62-64.

78. Park DS, Kim D, Hwang KE, et al. Diagnostic value and prognostic significance of pleural C-reactive protein in lung cancer patients with malignant pleural effusions. Yonsei Med J. 2013;54:396-402.

79. Görgün D, Seçik F, Midilli K, Akkaya V, Yıldız P. Diagnostic and prognostic significance of survivin levels in malignant pleural effusion Respir Med. 2013;107:1260-1265.

80. Abrao FC, de Abreu IR, Fogarolli M, et al. Prognostic factors of 30-day mortality after palliative procedures in patients with malignant pleural effusion. Ann Surg Oncol. 2015;22:4083-4088.
81. Anevlavis S, Kouliatsis G, Sotiriou I, et al. Prognostic factors in patients presenting with pleural effusion revealing malignancy. Respiration. 2014;87:311-316.

82. Zamboni MM, da Silva CT Jr, Baretta R, Cunha ET, Cardoso GP. Important prognostic factors for survival in patients with malignant pleural effusion. BMC Pulm Med. 2015;15:29.

83. Yoon DW, Cho JH, Choi YS, et al. Predictors of survival in patients who underwent video-assisted thoracic surgery talc pleurodesis for malignant pleural effusion. Thorac Cancer. 2016;7:393-398.

84. Fysh ET, Waterer GW, Kendall PA, et al. Indwelling pleural catheters reduce inpatient days over pleurodesis for malignant pleural effusion. Chest. 2012;142:394-400.

85. Penz E, Mishra E, Davies HE, Manns BJ, Miller RF, Rahman NM. Comparing cost of indwelling pleural catheter vs talc pleurodesis for malignant pleural effusion. Chest. 2014;146:991-1000.

86. Olfert JA, Penz ED, Manns BJ, et al. Cost-effectiveness of indwelling pleural catheter compared with talc in malignant pleural effusion. Respirology. Epub 2016 Dec 16.

87. Olden AM, Holloway R. Treatment of malignant pleural effusion: PleuRx catheter or talc pleurodesis? A cost-effectiveness analysis. J Palliat Med. 2010;13:59-65.

88. Puri V, Pyrdeck TL, Crabtree TD, et al. Treatment of malignant pleural effusion: a cost-effectiveness analysis. Ann Thorac Surg. 2012;94: 374-380.

89. Shafiq M, Frick KD, Lee H, Yarmus L, Feller-Kopman DJ. Management of malignant pleural effusion: a cost-utility analysis. J Bronchology Interv Pulmonol. 2015;22:215-225.

90. Psallidas I, Kalomenidis I, Porcel JM, Robinson BW, Stathopoulos GT. Malignant pleural effusion: from bench to bedside. Eur Respir Rev. 2016;25:189-198.

91. Rahman NM, Davies HE, Salzberg M, et al. Use of lipoteichoic acid-T for pleurodesis in malignant pleural effusion: a phase I toxicity and dose-escalation study. Lancet Oncol. 2008;9:946-952.

92. Lansley SM, Vergiliana JF, Cleaver AL, et al. A commercially available preparation of Staphylococcus aureus bio-products potently inhibits tumour growth in a murine model of mesothelioma. Respirology. 2014;19:1025-1033.

93. Han HS, Eom DW, Kim JH, et al. EGFR mutation status in primary lung adenocarcinomas and corresponding metastatic lesions: discordance in pleural metastases. Clin Lung Cancer. 2011;12:380-386.

94. Matsumori Y, Yano S, Goto H, et al. ZD6474, an inhibitor of vascular endothelial growth factor receptor tyrosine kinase, inhibits growth of experimental lung metastasis and production of malignant pleural effusions in a non-small cell lung cancer model. Oncol Res. 2006;16:15-26.

95. Pichelmayer O, Gruenberger B, Zielinski C, Raderer M. Bevacizumab is active in malignant effusion. Ann Oncol. 2006;17:1853.

96. Usui K, Sugawara S, Nishitsuji M, et al. A phase II study of bevacizumab with carboplatin-pemetrexed in non-squamous non-small cell lung carcinoma patients with malignant pleural effusions: North East Japan Study Group Trial NEJ013. Lung Cancer. 2016;99:131-136.

97. Astoul P, Viallat JR, Laurent JC, Brandely M, Boutin C. Intrapleural recombinant IL-2 in passive immunotherapy for malignant pleural effusion. Chest. 1993;103:209-213.
Cancer Management and Research

\section{Publish your work in this journal}

Cancer Management and Research is an international, peer-reviewed open access journal focusing on cancer research and the optimal use of preventative and integrated treatment interventions to achieve improved outcomes, enhanced survival and quality of life for the cancer patient. The manuscript management system is completely online and includes
Dovepress

a very quick and fair peer-review system, which is all easy to use. Visit http://www.dovepress.com/testimonials.php to read real quotes from published authors. 